\title{
SISTEMAS FOTOVOLTAICOS CONECTADOS À REDE ELÉTRICA NO BRASIL
}

José Waltrudes Castanheira Pereira - jose_waltrudes@id.uff.br

Universidade Federal Fluminense

Márcio Cataldi - marcio.cataldi@gmail.com

Universidade Federal Fluminense

Nathállia Miranda - nath.mercedes@gmail.com

Universidade Estadual do Rio de Janeiro 


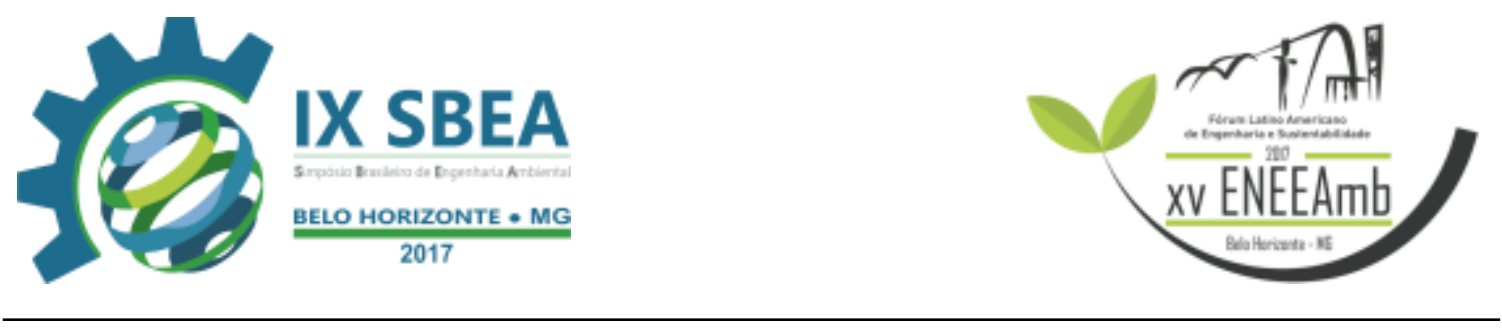

\section{RESUMO}

O trabalho expõe uma breve apresentação da utilização da energia solar para geração de energia elétrica, demonstrando os tipos de células fotovoltaicas e sua evolução. Dedicando, parte dele, em falar dos Sistemas Fotovoltaicos Conectados à Rede (SFCR), mostrando o seu funcionamento e seus prós e contras. Como principais vantagens, podem ser destacadas: é uma energia inesgotável, a manutenção dos sistemas é mínima e não há geração de poluentes ao meio ambiente na produção de energia, somente na produção dos materiais utilizados do sistema fotovoltaico. O Brasil possui um alto índice de radiação solar anual e é considerado um dos melhores países para a instalação de energia solar fotovoltaica. Nos últimos anos, o governo brasileiro tem mostrado uma evolução na área fotovoltaica, implementando regulamentações específicas e apresentando investimentos e financiamentos na área, com o objetivo de impulsionar o mercado fotovoltaico brasileiro. Setores privados também aumentaram seu interesse em investir nesta área, intensificando o atual crescimento da fonte solar no Brasil e no mundo.

Palavras-chave: Energia Solar, Sistemas Fotovoltaicos Conectados à Rede; Investimentos e Financiamentos.

\section{INTRODUÇÃO/OBJETIVO}

Este trabalho surge para aumentar o acervo do tema, de forma a esclarecer algumas questões e exibir o crescimento fotovoltaico brasileiro. Fundamentando na explicação da energia solar e no panorama brasileiro de sistemas fotovoltaicos conectados à rede elétrica.

Com objetivo principal de realizar uma revisão teórica do conhecimento em sistemas fotovoltaicos conectados à rede elétrica. Começando nos fundamentos da energia fotovoltaica até o estudo do cenário brasileiro nesta área.

\section{METODOLOGIA}

Inicialmente, foi realizado um levantamento bibliográfico do assunto energia solar. É um tema novo no Brasil, logo, para obter uma melhor comparação e materiais 
mais estruturados, buscou-se trabalhos, projetos e revistas internacionais com o objetivo de complementar a pesquisa. Com o material bibliográfico coletado e um entendimento melhor do assunto, estreitou-se a pesquisa para o assunto principal da pesquisa que é sobre sistemas fotovoltaicos conectados à rede elétrica no Brasil.

Com o objetivo de explorar o assunto de sistema fotovoltaico e torná-lo mais claro, o trabalho se divide em diferentes partes para melhor entendimento.

Começando com uma revisão literária apresentando maneiras de usar a energia solar, definindo as diferentes gerações de células fotovoltaicas, a evolução da energia solar e o funcionamento das células. A utilização do Atlas Solarimétrico Brasileiro surge para mostrar o alto potencial solar brasileiro. Em seguida, com o pequeno acervo encontrado e selecionado, colocou-se as principais regulamentações, investimentos e financiamentos do setor fotovoltaico brasileiro. Como é um setor muito recente no mercado brasileiro, o surgimento de novas regulamentações, investimentos e financiamentos são inevitáveis. Por esse motivo, o trabalho foi sendo atualizado até a sua finalização.

\section{RESULTADOS E DISCUSSÃO}

\section{Energia Solar}

A energia solar tem como fonte o sol e pode ser utilizada no aquecimento de água, por meio de coletores solares, e para geração de eletricidade, por meio de painéis fotovoltaicos. No meio rural, a energia elétrica gerada por meio dos painéis fotovoltaicos pode ser utilizada para uma série de finalidades, como iluminação, eletrificação rural, acionamento de motores e no bombeamento de água (NIEDZIALKOSKI, 2013).

A indústria fotovoltaica divide a tecnologia em três gerações que são as principais tecnologias aplicadas na produção de células e módulos fotovoltaicos (uma unidade básica formada por um conjunto de células fotovoltaicas) (PINHO; GALDINO, 2014). A primeira geração tem duas cadeias produtivas: silício monocristalino (m-Si) e silício policristalino (p-Si). Os monocristalinos que possuem uma homogeneização em toda sua extensão e o silício precisa ter um grau de pureza de 99,9999\% para a produção da célula fotovoltaica monocristalina (EPE, 2012). Ao contrário, o silício policristalino 


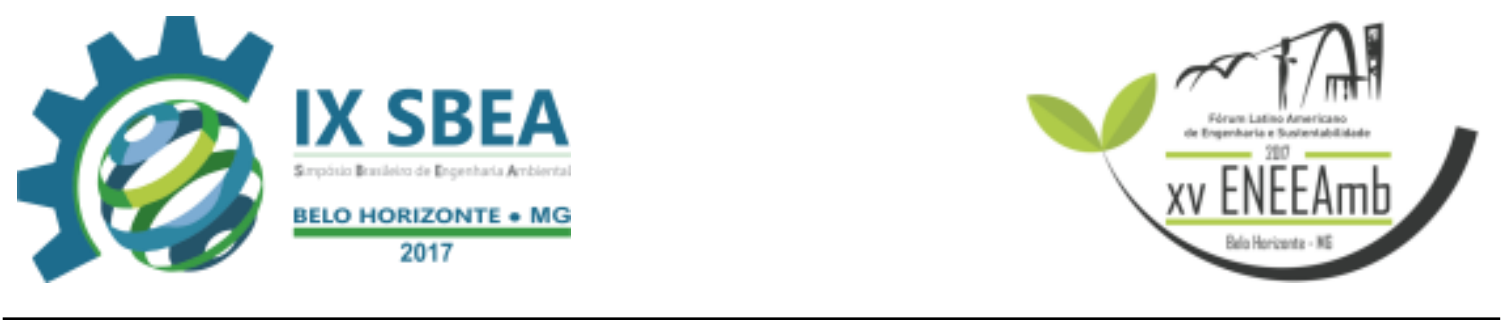

tem um menor gasto de energia e um menor rigor na fabricação. Isso torna o silício monocristalino mais caro, mas com uma maior eficiência na conversão de energia, $15 \%$ de eficiência média contra $13 \%$ de eficiência média do silício policristalino. (PINHO; GALDINO, 2014). A segunda geração, denominada de filmes finos, possui quatro cadeias produtivas: células de silício amorfo (a-Si), células de Telureto de Cádmio (CdTe), células de Disseleneto de Cobre e Índio (CIS) e células de Arseneto de Gálio (GaAs). Esta geração é menos eficiente que a primeira geração, cerca de 8 10\% (OLIVEIRA, 2008). A terceira geração engloba todas as tecnologias em fase de desenvolvimento e pesquisa. Tecnologias orgânicas, pontos quânticos, células multijunção, células portadores quentes e células solares sensibilizadas por corantes são os tópicos principais desta geração. Em geral, a terceira geração deve ser altamente eficiente, possuir baixo custo/watt e utilizar materiais abundantes e de baixa toxicidade.

\section{Funcionamento}

O trabalho foca na primeira geração, que é a de células fotovoltaicas, fabricadas com material semicondutor. As células fotovoltaicas são feitas de silício em forma pura. O cristal de silício puro não possui elétrons livres, ou seja, é considerado um mau condutor elétrico. Utiliza-se um processo chamado dopagem para alterar esta situação. Neste processo, se acrescentam porcentagens de outros elementos como o Fósforo e o Boro. Forma-se um material com elétrons livres ou com portadores de carga negativa (silício tipo N) na dopagem do silício com o elemento Fósforo. Na dopagem do silício com o elemento Boro, consegue-se um material com características inversas, isto é, um material com falta de elétrons ou com cargas positivas livres (silício tipo P). Cada célula fotovoltaica é composta de uma camada fina de material tipo $\mathrm{N}$ e outra com maior espessura de material tipo P (NASCIMENTO, 2004).

As duas camadas são eletricamente neutras quando estão separadas. Mas ao serem conectadas, na região P-N, forma-se um campo elétrico por ação dos elétrons livres do silício do tipo Negativo que preenchem os vazios da estrutura do silício do tipo Positivo (NASCIMENTO, 2004). Ao incidir luz sobre a célula fotovoltaica, os fótons, que foram absorvidos pelas células, chocam-se com outros elétrons da estrutura do silício e fornecem energia para gerar eletricidade. Devido ao campo elétrico gerado pela 


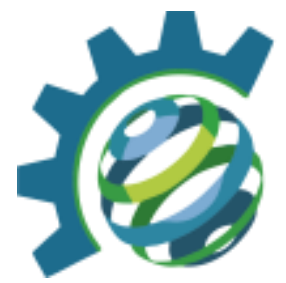

junção P-N, por meio da dopagem, os elétrons são levados da camada "P" para a camada "N". (NASCIMENTO, 2004). A Figura 1 exibe o passo a passo da geração de energia por meio de uma célula fotovoltaica.

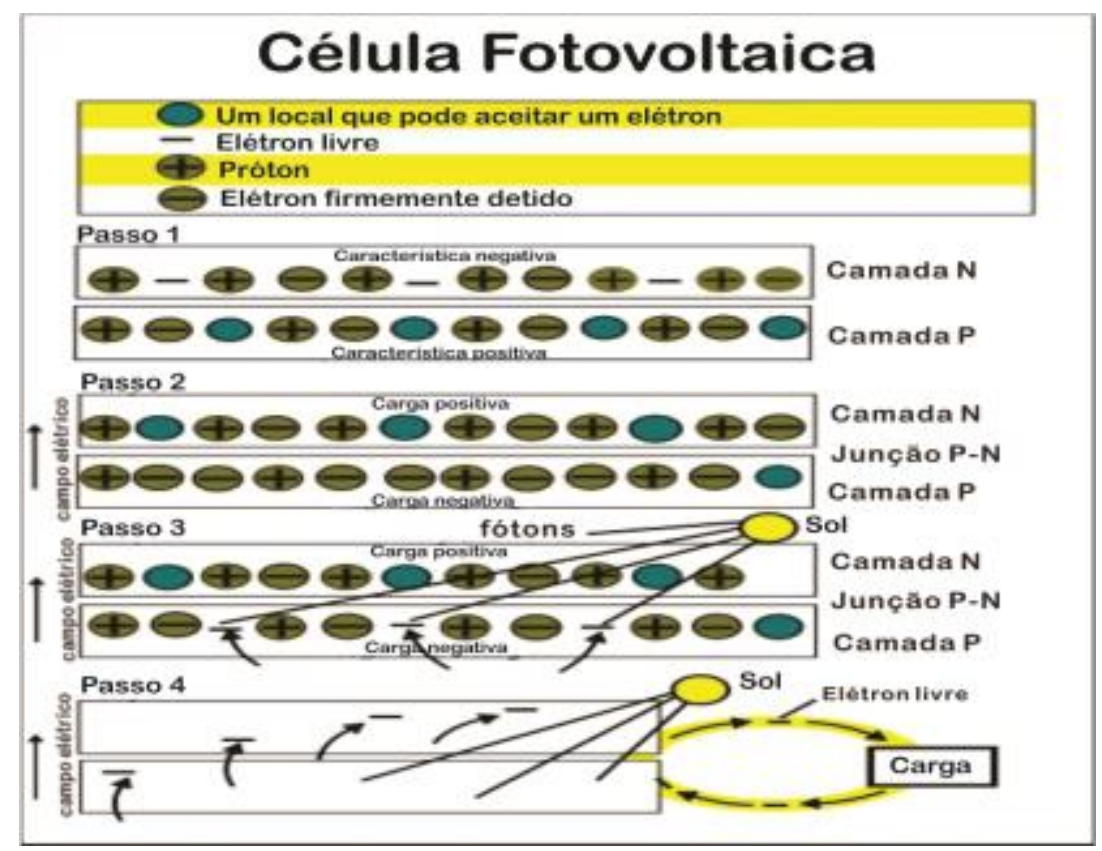

Figura 1. Funcionamento de uma célula fotovoltaica

Fonte: adaptado de ROMPICHERLA, 2013

A célula fotovoltaica é um equipamento fundamental para a construção de um sistema fotovoltaico conectado à rede elétrica. Os, Sistemas Fotovoltaicos Conectados à Rede (SFCR) apresentam duas configurações diferentes: os sistemas fotovoltaicos distribuídos e os sistemas fotovoltaicos centralizados. Os sistemas fotovoltaicos distribuídos conectados à rede são mais associados a uma edificação, ou seja, próximo do ponto de consumo (JANNUZZI, 2009). Eles também podem ser chamados de Sistemas Integrados a Edificações (SFIE). Já os sistemas fotovoltaicos centralizados conectados à rede, são usinas fotovoltaicas e normalmente se localizam a certa distância do ponto de consumo. Os SFCR não precisam de nenhum armazenamento de energia (baterias), já que toda energia produzida pode ser consumida diretamente pela carga, ou injetada na rede elétrica para ser consumida por outras unidades consumidoras. Estes sistemas são geralmente uma fonte complementar ao sistema elétrico ao qual está conectado (JANNUZZI, 2009). 


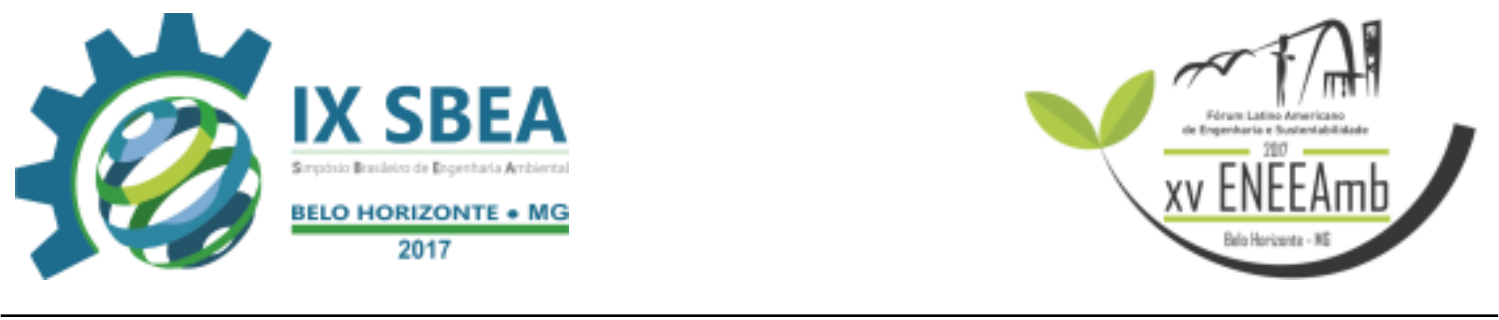

\section{Potencial brasileiro de geração solar}

Como dito anteriormente, o Brasil possui um grande potencial para gerar eletricidade a partir do sol e uma irradiação global relativamente bem distribuída pelas regiões brasileiras. O mapa anual de radiação solar global diária da Figura 2, tirado do Atlas Solarimétrico do Brasil, apresenta o desempenho de geração solar do Brasil.

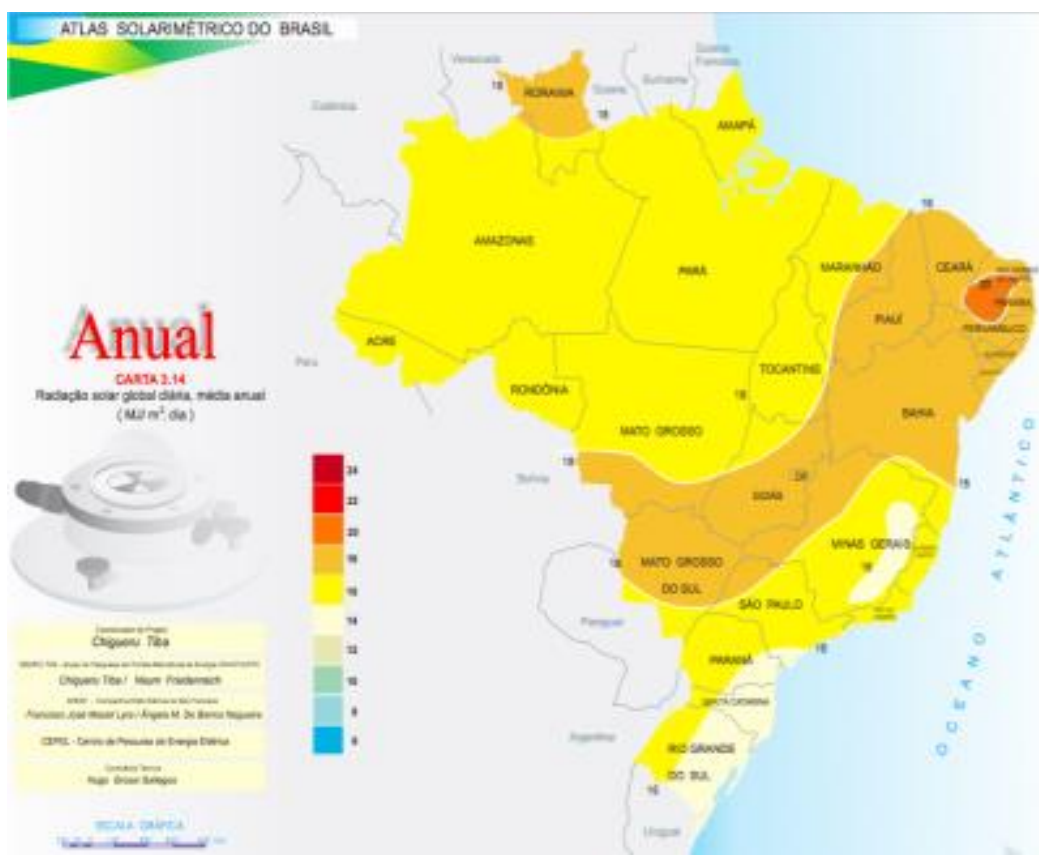

Figura 2. Radiação solar global diária, média anual

Fonte: Atlas Solarimétrico do Brasil, 2000

\section{Regulamentação no Brasil}

O Brasil tem uma regulamentação bem recente sobre os sistemas fotovoltaicos. Nela constam resoluções normativas da Aneel, portarias e ABNT NBRs. As Resoluções Normativas 482/2012 e 687/2015 da ANEEL, são ferramentas fundamentais na regulamentação de sistemas fotovoltaicos, elas estabelecem as condições gerais para a conexão à rede da microgeração (potência instalada menor ou igual a $75 \mathrm{~kW}$ ) e minigeração (potência instalada entre $75 \mathrm{~kW}$ e $5 \mathrm{MW}$ ) distribuída no Brasil e pelo Sistema de Compensação de Energia (ANEEL, 2016). Estas Resoluções permitem que sistemas fotovoltaicos se conectem à rede elétrica de forma simplificada, atendendo o 


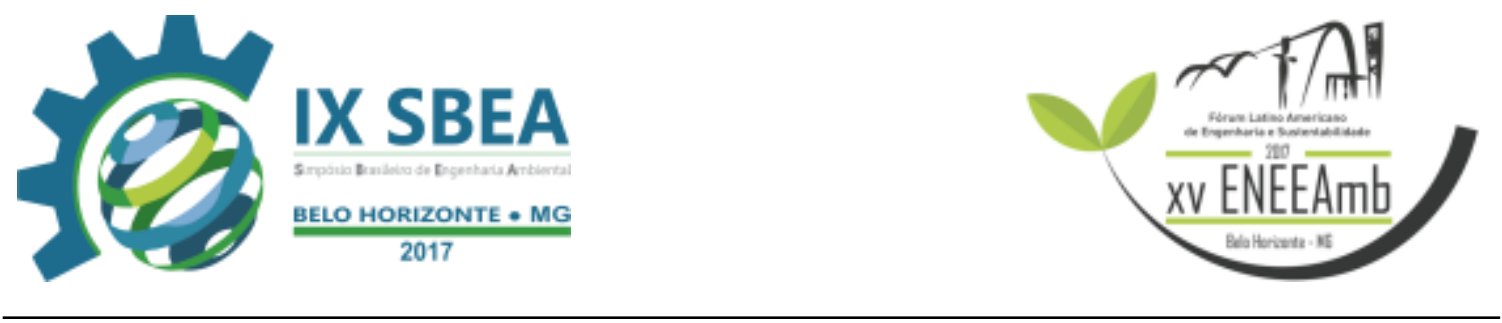

consumo local e injetando o excedente na rede, gerando créditos de energia (PINHO; GALDINO, 2014).

\section{Influência política na geração de energia renovável no Brasil}

Atualmente, existe um obstáculo de natureza institucional no setor elétrico brasileiro. Desde 2012, o setor elétrico tem sido objeto de várias alterações regulatórias (medidas provisórias, leis, decretos, resoluções, etc.). Isso aumenta a impressão do risco e da incerteza dos investidores, fazendo com que estes agentes retardem e reavaliem seus planos de alocar recursos em projetos do setor elétrico. Portanto, os investidores precisam de tempo para assimilarem as mudanças e, posteriormente, destinarem os recursos em projetos de maior risco, como aqueles relacionados com a geração de energia solar. Com o tempo necessário, o Brasil pode fortalecer o mercado interno de equipamentos para energia solar e reduzir o risco de investir e desenvolver a fonte de energia solar (SILVA, 2015).

\section{Investimentos em energia solar}

Tudo começou em 2011, quando a Aneel lançou a chamada no 13/2011 para um Projeto Estratégico de $\mathrm{P} \& \mathrm{D}$, chamado Arranjos Técnicos e Comerciais para Inserção da Geração Solar Fotovoltaica na Matriz Energética Brasileira. No edital, foram selecionados 18 projetos de sistemas fotovoltaicos centralizados conectados à rede elétrica com potência instaladas entre 0,5 MWp e 3MWp, totalizando uma potência instalada de 24,6 MWp, com o custo do projeto de 396 milhões de reais. Em 31 de outubro de 2014 foi realizado o primeiro leilão, voltado para a geração de energia solar centralizada, com capacidade instalada de 890 MW. Em 2015, mais dois leilões, foram realizados, totalizando 2.653 MW contratados, com início de suprimento em 2017 e 2018. Os leilões foram feitos na modalidade de energia de reserva (LER), com o objetivo de promover o uso da energia solar fotovoltaica no Brasil, além de incentivar a indústria no país. A Tabela 1 mostra mais detalhes destes três leilões voltados para estimular a geração solar centralizada no Brasil. 


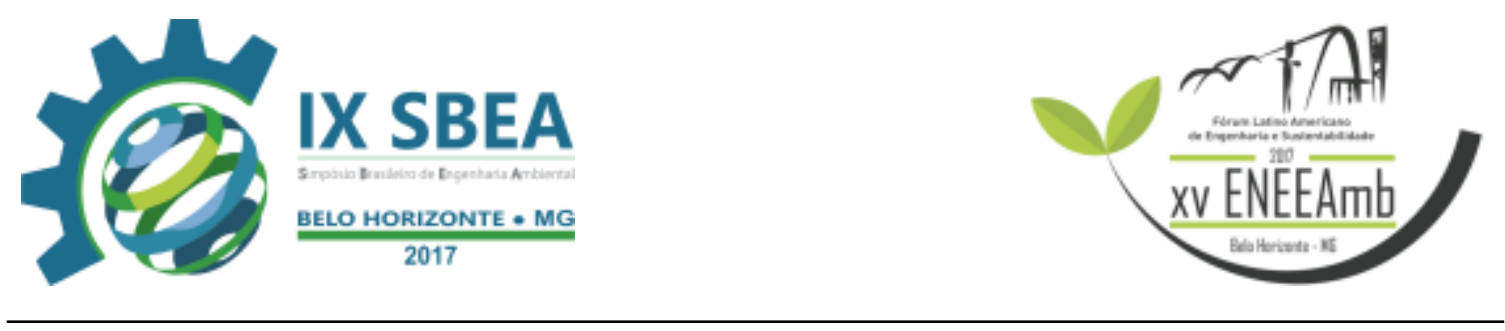

Tabela 1. Leilões brasileiros de Geração Solar centralizada

\begin{tabular}{|c|c|c|c|c|c|c|c|}
\hline $\begin{array}{l}\text { Mês/ } \\
\text { Ano }\end{array}$ & $\begin{array}{c}\text { Projetos } \\
\text { Contra- } \\
\text { tados }\end{array}$ & $\begin{array}{l}\text { Capaci- } \\
\text { dade } \\
\text { Instalada } \\
\text { (MW) }\end{array}$ & $\begin{array}{c}\text { Energia } \\
\text { Contra- } \\
\text { tada } \\
\text { (MWe) }\end{array}$ & $\begin{array}{c}\text { Início } \\
\text { de } \\
\text { Supri- } \\
\text { mento }\end{array}$ & $\begin{array}{c}\text { Período } \\
\text { Contra- } \\
\text { tado } \\
\text { (anos) }\end{array}$ & $\begin{array}{c}\text { Preço de } \\
\text { Venda } \\
\text { (R\$/ } \\
\text { MWh) }\end{array}$ & $\begin{array}{c}\text { Preço de } \\
\text { Venda } \\
\text { (U\$/ } \\
\text { MWh) }\end{array}$ \\
\hline $10 / 2014$ & 31 & 890 & 202 & 2017 & 21 & 215,5 & 88,2 \\
\hline 08/2015 & 30 & 834 & 232 & 2017 & 21 & 301,6 & 84,3 \\
\hline $11 / 2015$ & 33 & 929 & 245 & 2018 & 21 & 297,4 & 78,2 \\
\hline Total & 94 & 2.653 & 679 & & & & \\
\hline
\end{tabular}

Fonte: Ministério de Minas e Energia, 2015

Outra ação relevante nesta área de geração de energia fotovoltaica, foi a criação do Programa de Desenvolvimento da Geração Distribuída de Energia Elétrica (ProGD) pelo Ministério de Minas e Energia em dezembro de 2015. O ProGD, criado pela portaria $\mathrm{N}^{\circ} 538$, pode movimentar pouco mais de $\mathrm{R} \$ 100$ bilhões em investimentos, até 2030.

\section{Financiamentos brasileiros para energia solar}

Atualmente, empresas e consumidores domésticos contam com isenções de impostos e linhas de financiamento especificas para adquirir equipamentos de geração de energia solar com uma maior facilidade. A isenção de impostos é uma das mais importantes ferramentas para alavancar setores que precisam de incentivos como o setor solar brasileiro. As principais isenções são: Isenção do Imposto Sobre Circulação de Mercadorias (ICMS) para as operações com equipamentos e componentes para o aproveitamento de energia solar e a Redução do Imposto de Importação de 14\% para $2 \%$ incidente sobre bens de capital destinados à produção de equipamentos de geração solar fotovoltaica (ENERGIA, 2015). O Brasil também possui diversas linhas de financiamento voltadas para energia solar, com o objetivo de alavancar o mercado fotovoltaico do país. Destacando as linhas de financiamento do Banco Nacional do Desenvolvimento (BNDES) com o fundo clima, da Caixa Econômica Federal, do Banco do Brasil, do Banco do Nordeste com o FNE Sol, a Linha de Financiamento Economia Verde do Governo de São Paulo e a Sicredi (instituição financeira particular). 


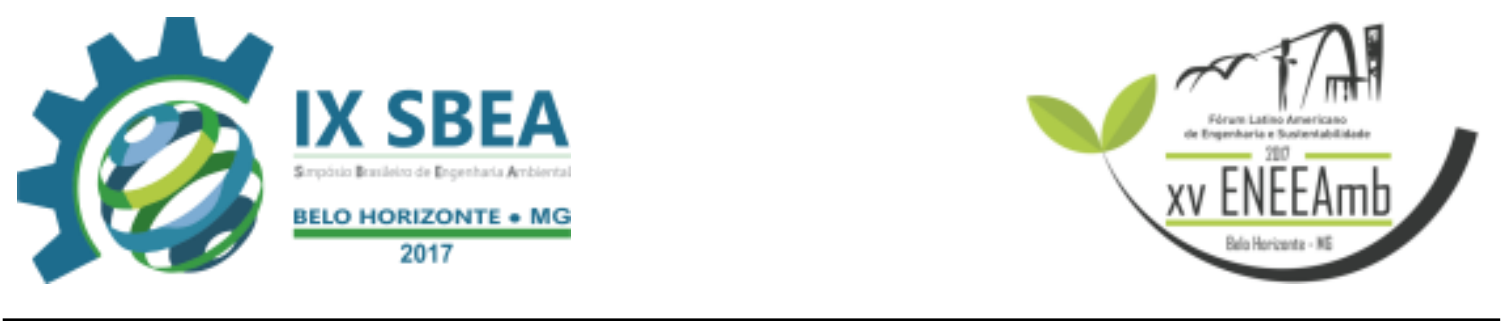

\section{CONCLUSÕES/RECOMENDAÇÕES}

O Brasil vem aperfeiçoando o seu mecanismo regulatório referente a energia fotovoltaica. Com a implementação da Resolução Normativa 482/2012, todo gerador de energia fotovoltaica pode diminuir sua conta elétrica, inserindo a energia excedente na rede elétrica da concessionária. Essa Resolução e outras atividades, relacionadas com a redução de custos na produção de energia solar fotovoltaica, têm a intenção de derrubar barreiras e facilitar a utilização de Sistemas Fotovoltaicos Conectados à Rede.

A energia fotovoltaica ainda tem uma participação reduzida na matriz energética nacional, apesar do seu elevado potencial de aproveitamento de energia solar. Mas o país vem tentando ao longo dos anos estimular a fonte solar fotovoltaica, esperando, para o futuro, uma maior participação da fonte solar no quadro energético brasileiro. A atual situação financeira e política brasileira se torna um sério obstáculo para o crescimento do mercado fotovoltaico nacional. Um exemplo de redução de investimentos na energia solar foi o cancelamento do $2^{\circ}$ Leilão de Energia de Reserva (LER), que seria no dia 19 de dezembro de 2016, com a meta de reduzir as projeções de carga de energia elétrica para os próximos anos. Sendo assim, pode-se concluir que mesmo com atividades e regulamentações voltadas para a redução do custo do sistema fotovoltaico, a crise atual interrompe todas as estimativas positivas da área fotovoltaica brasileira. Uma opção para vencer essa crise está nas células fotovoltaicas orgânicas da terceira geração de células fotovoltaicas. As células fotovoltaicas orgânicas podem ser a esperança para superar as dificuldades, contando com um custo inicial baixo e um menor impacto ambiental em sua fabricação, se compararmos com as células tradicionais de silício.

\section{REFERÊNCIAS BIBLIOGRÁFICAS}

ALVARENGA, C. A. O módulo fotovoltaico para gerador solar de eletricidade. $n$. 31, p. 1-9, [s.d.].

ANEEL. Agência Nacional de Energia Elétrica - ANEEL Procedimentos de Distribuição de Energia Elétrica no Sistema Elétrico Nacional - PRODIST Módulo 3 - Acesso ao Sistema de Distribuição. [s.l: s.n.].

CEPEL. ENERGIA SOLAR. [s.l: s.n.]. 
CONFAZ. Convênio ICMS. p. 15-17, 2016.

ENERGIA, M. DE M. E. Energia Solar no Brasil e Mundo. n. 55 61, p. 4, 2015.

EPE, C. Análise da Inserção da Geração Solar na Matriz Elétrica Brasileira. [s.l: s.n.].

FRANCO, A. P. Sistemas Fotovoltaicos: Contextualização e Perspectivas para sua Massificação no Brasil. [s.l: s.n.].

FTHENAKIS, V. M.; KIM, H. C.; ALSEMA, E. Emissions from Photovoltaic Life Cycles Emissions from Photovoltaic Life Cycles. Environmental Science and Technology, v. 42, n. 6, p. 2168-2174, 2008.

JANNUZZI, M. et al. RELATÓRIO FINAL Sistemas Fotovoltaicos Conectados à Rede Elétrica no Brasil: Panorama da Atual Legislação. [s.l: s.n.].

NASCIMENTO, C. A. DO. PRINCÍPIO DE FUNCIONAMENTO DA CÉLULA FOTOVOLTAICA. [s.l: s.n.].

NIEDZIAlKoski, R. K. Desempenho De Painéis Solares Mono E Policristalinos Em Um Sistema De Bombeamento De Água. [s.l: s.n.].

OLIVEIRA, H. E. Tecnologia Fotovoltaica em filmes finos (películas delgadas). [s.l.] Universidade Federal de Lavras, 2008.

PINHO, J. T.; GALDINO, M. A. Manual de Engenharia para Sistemas Fotovoltaicos. Rio de Janeiro: CEPEL - CRESESB, 2014.

RAUSCHMAYER, H. O retorno financeiro da microgeração. [s.d.].

ROMPICHERLA, S. M. Solar Energy: The Future. International Journal of Engineering Trends and Technology, v. 4, n. 6, p. 2513-2517, 2013.

SILVA, R. MA. DA. ENERGIA SOLAR NO BRASIL: dos incentivos aos desafios. p. 53, 2015.

TIBA, C. Atlas Solarimétrico do Brasil: Banco de Dados Terrestres. [s.l: s.n.]. v. 1 ANEEL, $\quad 2016 \quad<\quad$ http://www.aneel.gov.br/informacoes-tecnicas//asset_publisher/CegkWaVJWF5E/content/geracao-distribuida-introduc1/656827?inheritRedirect=false > Acessado em: 23 de dezembro. 2016. 